\title{
Producing Capabilities of Interferon-gamma and Interleukin-10 in Periph- eral Blood from Oral Squamous Cell Carcinoma Patients
}

\author{
Kosuke Naganawa, 1,2,\#, Eiji Takayama,", Makoto Adachi ${ }^{2,3, \#}, K^{1, \# j i ~ M i t s u d o ~}{ }^{3, \#}$, Masaki Iida,, , \\ Masako Kamiya-Mizuno ${ }^{1}$, Harumi Kawaki ${ }^{1}$, Masao Ichinose ${ }^{4}$, Masayuki Motohashi ${ }^{2}$, \\ Yasunori Muramatsu $^{2}$, Iwai Tohnai ${ }^{3}$, Shin-Ichiro Sumitomo ${ }^{2}$, Michio Shikimori $^{2}$ and \\ Nobuo Kondoh ${ }^{1, *}$
}

\begin{abstract}
${ }^{1}$ Department of Oral Biochemistry, School of Dentistry, Asahi University, 1851 Hozumi, Mizuho, Gifu 501-0296, Japan; ${ }^{2}$ Department of Oral and Maxillofacial Surgery, School of Dentistry, Asahi University, 1851 Hozumi 1851-1, Mizuhoshi, Gifu 501-0296, Japan; ${ }^{3}$ Department of Oral and Maxillofacial Surgery, Yokohama City University Graduate School of Medicine, 3-9 Fukuura, Yokohama, Kanagawa 236-0004, Japan; ${ }^{4}$ Second Department of Internal Medicine, Wakayama Medical University, 811-1 Kimiidera, Wakayama 641-0012, Japan
\end{abstract}

\begin{abstract}
In order to evaluate the Th1 and Th2 responses of Oral Squamous Cell Carcinoma (OSCC) patients, we investigated the cytokine producing capability of peripheral blood (PB), and compared it with clinicopathological appearances of OSCC patients. The production of a Th1-type cytokine, interferon (IFN)- $\gamma$, from lipopolysaccharide (LPS)-stimulated PB correlated positively with the frequency of lymph node metastasis. We also investigated the production of a Th2-type cytokine, IL-10, however, no significant correlation was observed with the clinicopathological appearances. Our results suggested that the IFN- $\gamma$ producing capability was specifically regulated and dependent on the regional metastatic potencies of OSCCs.
\end{abstract}

Keywords: Cytokine-producing capability, interferon-gamma (IFN- $\gamma$ ), Oral squamous cell carcinoma, peripheral blood, tumor immunology.

\section{INTRODUCTION}

OSCC is the most frequent malignant tumor of the oral cavity, representing more than $80 \%$ of all oral malignancies [1]. For patients with locally advanced OSCC, surgery, with or without radiotherapy, has been widely accepted as the standard treatment and is thought to be the most curative therapy. However, the disease still has a low overall survival rate of about $60 \%$ [2], and for many OSCC patients, it remains difficult to predict the risk of metastasis and offer a reliable prognosis.

Depending on the cytokine profile, the immune responses have been, at least, classified into 2 functionally distinct helper $\mathrm{T}$ cell subsets. The cytokines produced by the Th1 and Th2 cell subsets are important for the effective function and immune response of $\mathrm{T}$ lymphocytes to regulate the distinct differentiation of these cells. The cytokine products of Th1 and Th2 cells are mutually inhibitory for the differentiation and effect or function of the reciprocal phenotype. This regulation may explain the biases of the Th1 and Th2 responses [3, 4]. It has been reported that an imbalance

\footnotetext{
*Address correspondence to this author at the Department of Oral Biochemistry, School of Dentistry, Asahi University, 1851 Hozumi, Mizuho, Gifu 501-0296, Japan; Tel: +81-058-329-1416; Fax: +81-058-329-1417;

E-mail: kondoh@dent.asahi-u.ac.jp

\#These authors contributed equally to this work.
}

between Th1 and Th2 immune response has a correlation with immune dysregulation in various malignancies. The Th1 and Th2 balance has been evaluated in bladder carcinoma [5], colorectal cancer [6, 7], breast cancer [8] and melanoma [9] patients. These studies comparing the Th1/Th2 balance of cancer patients demonstrated that there was a Th1 deficit in cancer patients, while Th2 cytokine was found to be increased. In line with these observations, we have also demonstrated that the IFN- $\gamma$ producing capability from LPS-stimulated PB is significantly reduced in gastric cancer [10] and hepatocellular carcinoma patients [11].

In this study, we examined the Th1/Th2 cytokine producing capability of $\mathrm{PB}$, and evaluated the diagnostic significance for OSCC patients.

\section{MATERIALS AND METHODS}

\section{Patients with Oral Squamous Cell Carcinoma}

Seventy-two patients with OSCC treated at Yokohama City University Hospital and Asahi University School of Dentistry between April 2010 and March 2013 were enrolled in the present study (44 men, 28 women; mean (standard deviation / SD) age 65.0 (15.4) years, range 32-92 years) (Table 1). The histopathological characteristics were diagnosed with a biopsied tumor specimen. Clinical staging, including information of tumor sizes, lymph node status and 
Table 1. Clinicopathologic parameters of the enrolled patients with OSCC.

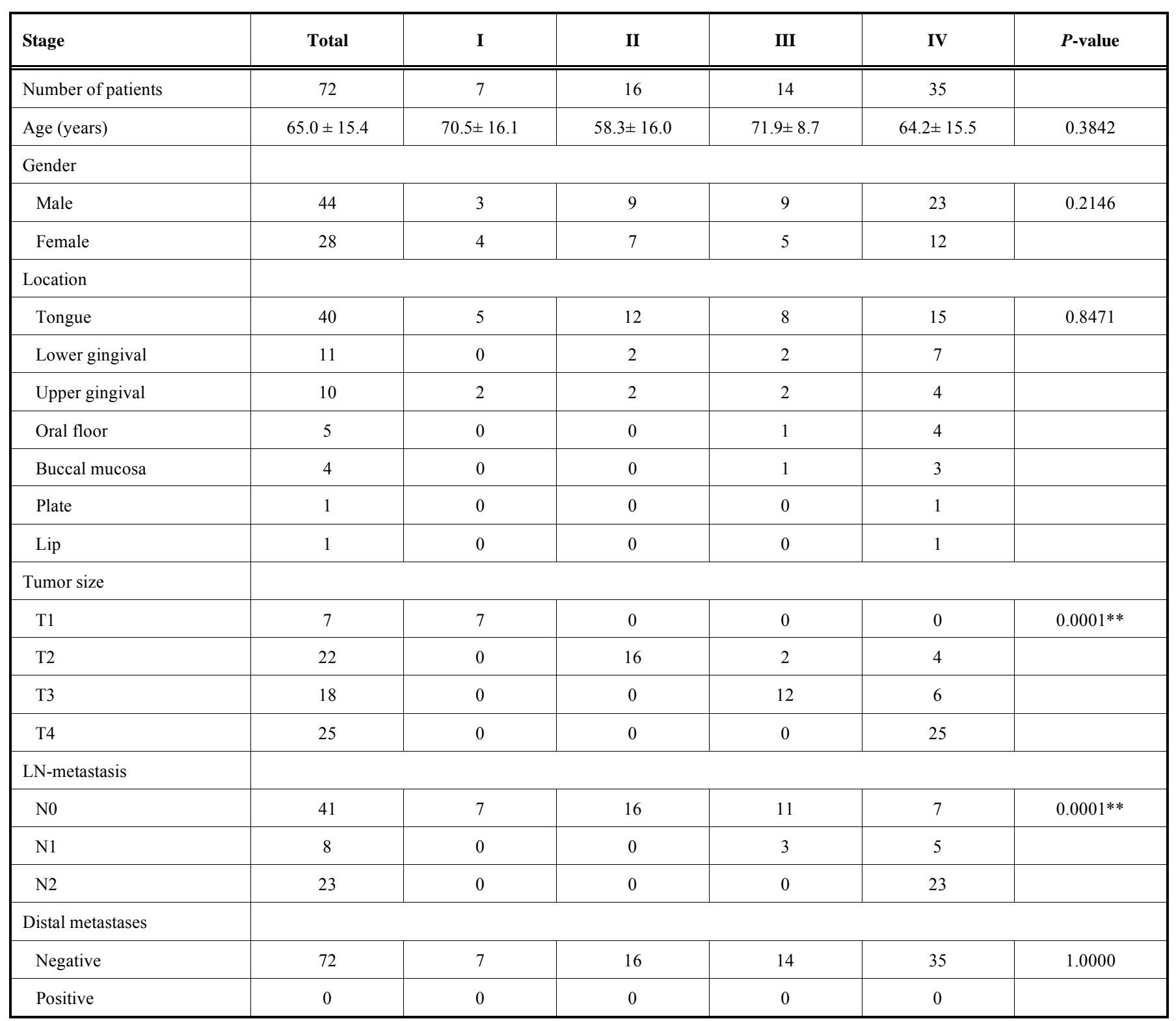

The clinical staging and TNM classification were based on the UICC staging system as described (Sobin L, et al.). $\left({ }^{*} p<0.05,{ }^{* * *} p<0.01\right)$

histopathological grading was determined according to the Union Internationale Contre le Cancer TNM Classification [12]. The ethics committees of Asahi University School of Dentistry (20071) and Yokohama City University Hospital (B10010728) approved the study protocols, and informed consent was obtained from all patients prior to initiation of the study.

\section{Cytokine-producing Capabilities of PB}

The established method for determining the cytokineproducing capabilities of PB has already been described in previous reports [11]. Briefly, less than 1 milliliter $(>0.1 \mathrm{ml})$ of peripheral blood was stored in a tube containing sodium heparin (Terumo Medical Products, Japan) at room temperature and was used for the subsequent assay within $24 \mathrm{~h}$. Peripheral blood $(0.1 \mathrm{ml})$ was added to $0.1 \mathrm{ml}$ of serum-free RPMI-1640 medium (R8758, Sigma-Aldrich, USA), placed in a 96 well plate $(3599$, Costar, USA), then incubated with $0.5 \mu \mathrm{g} / \mathrm{ml}$ of LPS (L2654, Sigma-Aldrich) for $24 \mathrm{~h}$ under $5 \% \mathrm{CO}_{2}$ at $37^{\circ} \mathrm{C}$. The supernatant was harvested, and then stored at $-80^{\circ} \mathrm{C}$ until ELISA analysis. Cytokine production (IFN- $\gamma$ and IL-10) was measured using ELISA kits (OptEIA ELISA Set, BD Bioscience, USA).

\section{Statistics}

All analyses were performed using statistical software (Stat Mate Version 4.0 ATOMS; JAPAN). Data are expressed as means \pm standard deviation (SD) and standard deviation error. Welch's t-test was applied to determine the significance of differences between two groups. One-way ANOVA was applied to reveal the significance of overall differences among the groups. $P$ values less than 0.05 were considered to be statistically significant. 
A

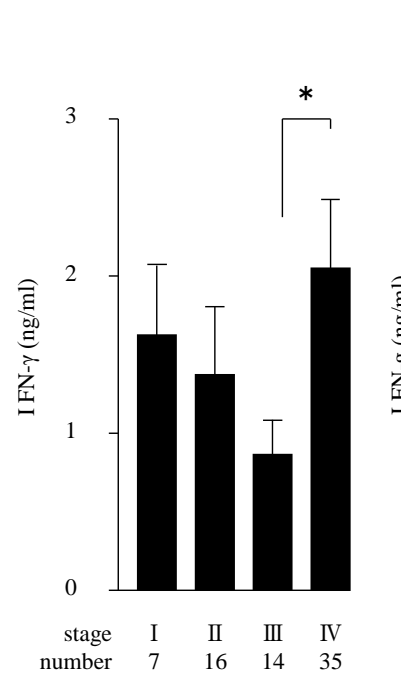

B

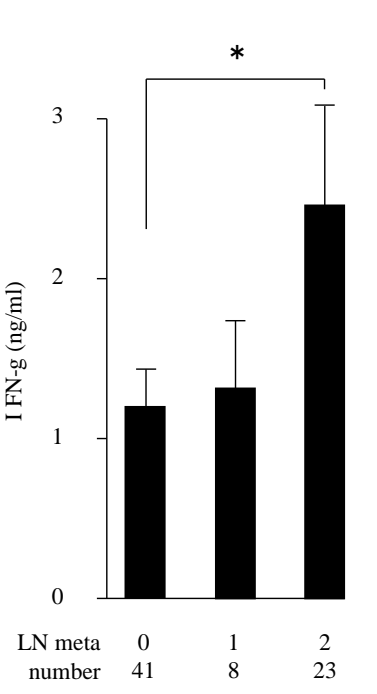

$\mathrm{C}$

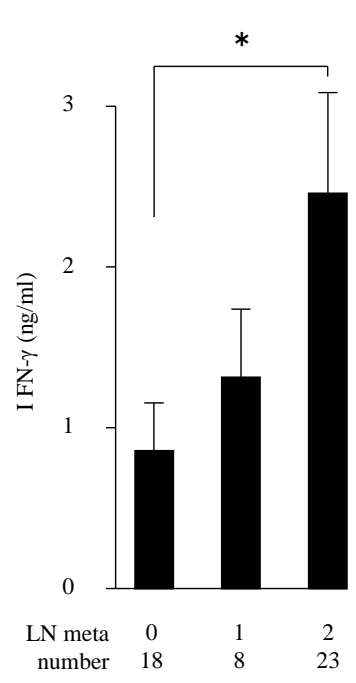

$\mathrm{D}$

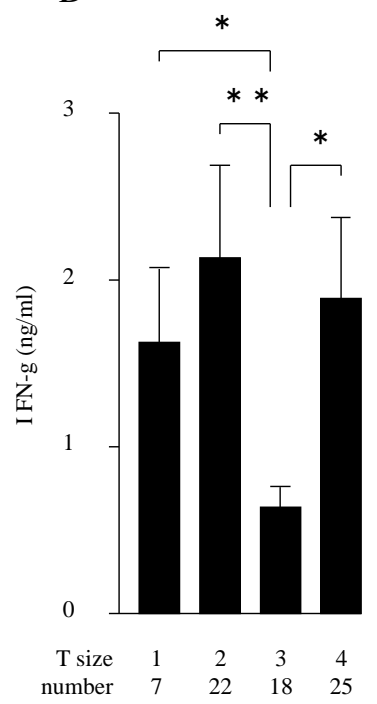

Fig. (1). LPS-induced IFN- $\gamma$ production in PB from 72 OSCC patients (A, B, D), or from the 49 patients in stages III and IV (C). Amounts of IFN- $\gamma(\mathrm{ng} / \mathrm{ml})$ are in ordinate, and samples classified with corresponding tumor stages $(\mathbf{A})$, lymphnode metastases $(\mathbf{B}, \mathbf{C})$ and tumor sizes $(\mathbf{D})$ are denoted in abscissa, respectively. $(* \mathrm{p}<0.05, * * \mathrm{p}<0.01)$. Error bar shows SD.

\section{RESULTS}

\section{Clinicopathological Appearances}

The clinicopathological appearances of 72 OSCC patients were summarized in Table 1 . The median age of the patients was 68 (range, 32-92) yr. Lymph node metastasis and tumor sizes correlated with clinical stages, which were determined according to the TNM classification [12]. On the other hand, age and gender showed no prognostic significance in the clinical stages (Table 1).

\section{Cytokine-producing Capability of PB from OSCC Pa- tients}

We attempted to examine plasma cytokine levels, however, the levels of IFN- $\gamma$ and IL-10 in our group of OSCC patients were unchanged (or undetected) at all measured stages (data not shown). We determined the production of Th1 cytokine IFN- $\gamma$ from LPS-stimulated PB using ELISA analysis. As shown in Fig. (1A), the IFN- $\gamma$-producing capability was high in stage I patients, but was somewhat decreased in stage II and III tumor progressions. However, the highest level was seen in stage IV patients. Since the clinical staging mainly comprises parameters including primary tumor sizes (from grade T1 through T4) and local metastases (from N0 to N3 in Table 1) [12], we separately compared the IFN- $\gamma$-producing capability with each parameter. As shown in Fig. (1B), the IFN- $\gamma$-producing capability was significantly increased according to the severity of lymph node metastases among the 72 patients; this tendency was significant in 49 patients in the advanced stages, III and IV (Fig. (1C)). On the other hand, the IFN- $\gamma$-producing capability fluctuated among the samples of different T-grades, in which no particular propensity was observed Fig. (1D).

We also examined the production of a Th2 cytokine, IL10, in LPS-stimulated PB from the 72 patients. The IL-10- producing capability was unchanged among patients with different stages, lymph node status or T-grades (Fig. 2A, B and $\mathbf{C}$ ).

\section{DISCUSSION}

IFN- $\gamma$ and IL-10 are secreted by various leukocytes and modulate immune function in the tumor micro environment. IFN- $\gamma$ has been shown to promote host antitumor immunity since the mice in these studies that were deficient in IFN- $\gamma$ signaling proved susceptible to carcinogen-induced tumor formation [13]. In this study, we demonstrated that IFN- $\gamma$ producing capability increased according to the severity of lymph node metastasis; this tendency was significant in advanced stages, III and IV, in which all of the metastatic cases are included. IFN- $\gamma$ is produced by Th1, as well as natural killer (NK) cells, and stimulates inflammatory cells including NK cells to induce functional and morphological changes [14]. LPS primarily activates dendritic cells or macrophages through Toll-like receptor 4 (TLR4), triggering cytokines and stimulating surface ligands, leading to NK cell activation [15], however, it can also induce IFN- $\gamma$ that is distinct from TLR4-mediated signaling pathways[16]. It has been reported that head and neck cancer patients with advanced lymphnode metastases accompanied by extranodal disease show high levels of NK cell cytotoxicity [17]. Therefore, our observations upon IFN- $\gamma$ may in part be associated with the NK cell-mediated activity.

It has been reported that IL-10 is also produced by OSCC as well as dysplastic cells, while IFN- $\gamma$ and IL-10 are primarily produced by inflammatory cells. These reports demonstrated that a combination of low IFN- $\gamma$ and high IL-10 levels were associated with a poor prognosis [18]. In cervical cancer, important regulatory roles in cancer-mediated immunosuppression are mainly mediated by IL-10 and TGF-B [19]. However, our results demonstrated that the IL-10 producing capability by PBCs was not significantly changed 

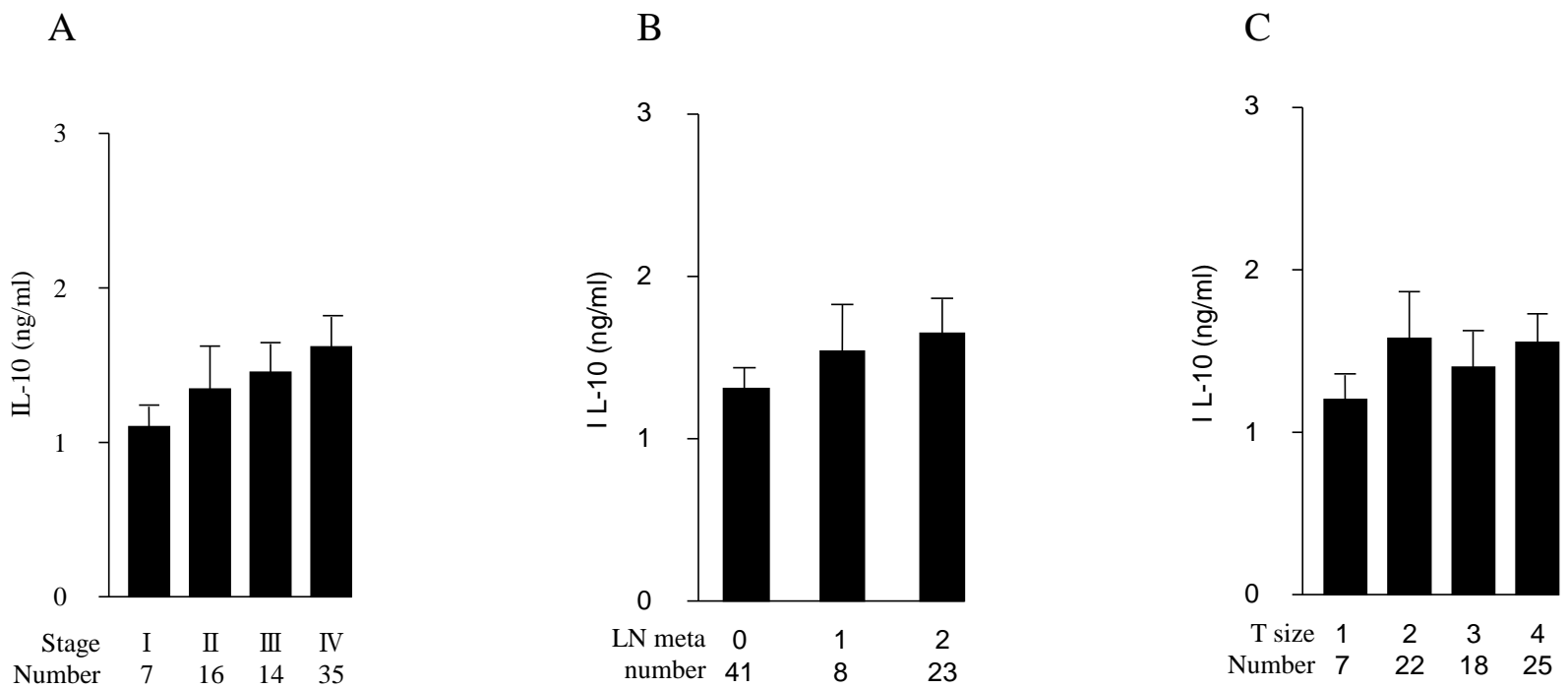

Fig. (2). LPS-induced IL-10 production in PB from 72 OSCC patients. Amounts of IL-10 (ng/ml) are in ordinate, and samples classified with corresponding tumor stages (A), lymphnode metastases $(\mathbf{B})$ and tumor sizes $(\mathbf{C})$ are denoted in $a b s c i s s a$, respectively $(* \mathrm{p}<0.05, * * \mathrm{p}<0.01)$. Error bar shows SD.

among OSCC patients even though they were in different stages, and had varying tumor sizes and lymph node status.

So far, we have been unable to explain the regulatory mechanisms of IFN- $\gamma$-producing capability in tumor milieu. However, since the NK cell activity correlates well with the disease free interval after definitive therapy [17], the IFN- $\gamma$ producing capability of $\mathrm{PB}$ could also provide a promising prognostic significance for OSCC patients.

\section{ABBREVIATIONS}

$$
\begin{aligned}
& \text { OSCC }=\text { Oral Squamous Cell Carcinoma } \\
& \text { IFN- } \gamma=\text { interferon-gamma } \\
& \text { PB }=\text { peripheral blood } \\
& \text { LPS }=\text { lipopolysaccharide } \\
& \text { IL-10 }=\text { Interleukin-10 }
\end{aligned}
$$

\section{CONFLICT OF INTEREST}

The authors confirm that this article content has no conflict of interest.

\section{ACKNOWLEDGEMENTS}

This work was supported in part by the Grants-in-Aid for Scientific Research from the Japan Society for the Promotion of Science (23592976).

\section{REFERENCES}

[1] Gao W, Guo CB. Factors related to delay in diagnosis of oral squamous cell carcinoma. J Oral Maxillofac Surg 2009; 67: 101520.

[2] McDowell L, Collins M, Kleid S, Rischin D, Corry J. T4 squamous cell carcinoma of the oral tongue without mandibular involvement: surgery or chemoradiotherapy? Oral Surg Oral Med Oral Pathol Oral Radiol 2014; 117: 163-9.
[3] Jung T, Lack G, Schauer U, et al. Decreased frequency of interferon-gamma- and interleukin-2-producing cells in patients with atopic disease measured J. Allergy Clin Immunol 1995; 96:515-27.

[4] Meyaard L, Hovenkamp E, Keet IP, et al. Single cell analysis of IL-4 and IFN-gamma production by T cells from HIV-infected individuals: decreased IFN-gamma in the presence of preserved IL-4 production. J Immunol 1996; 157: 2712-18.

[5] Agarwal A, Verma S, Burra U, Murthy NS, Mohanty NK, Saxena S. Flow cytometric analysis of Th1 and Th2 cytokines in PBMCs as a parameter of immunological dysfunction in patients of superficial transitional cell carcinoma of bladder. Cancer Immunol Immunother 2006; 55(6): 734-43.

[6] Matsuda A, Furukawa K, Takasaki H, et al. Preoperative oral immune-enhancing nutritional supplementation corrects TH1/TH2 imbalance in patients undergoing elective surgery for colorectal cancer. Dis Colon Rectum 2006; 49(4): 507-16.

[7] Pellegrini P, Berghella AM, Del Beato T, Cicia S, Adorno D, Casciani CU. Disregulation in TH1 and TH2 subsets of $\mathrm{CD} 4^{+} \mathrm{T}$ cells in peripheral blood of colorectal cancer patients and involvement in cancer establishment and progression. Cancer Immunol Immunother 1996; 42: 1-8

[8] Krohn M, Listing M, Tjahjono G, et al. Depression, mood, stress, and Th1/Th2 immune balance in primary breast cancer patients undergoing classical massage therapy. Support Care Cancer 2011; 19(9): 1303-11.

[9] Lee KY, Goedegebuure PS, Linehan DC, Eberlein TJ. Immunoregulatory effects of $\mathrm{CD}^{+} \mathrm{T}$ helper subsets in human melanoma. Surgery 1995; 117: 365-72.

[10] Magari H, Takayama E, Ichinose M. Gastroentrol 2007; 32: A621.

[11] Shiraki T, Takayama E, Magari $\mathrm{H}$, et al, Altered cytokine levels and increased $\mathrm{CD} 4^{+} \mathrm{CD} 57^{+} \mathrm{T}$ cells in the peripheral blood of hepatitis C virus-related hepatocellular carcinoma patients. Oncol Rep 2011; 26: 201-8.

[12] Sobin LH, Gospodarowicz MK, Wittekind C. International Union Against Cancer. TNM classification of malignant tumors. $7^{\text {th }}$ ed. New York: Wiley-Blackwell 2009; pp. 25-9.

[13] Dunn GP. OldLJ. Schreiber RD. The three Es of cancerimmunoediting. Annu Rev Immunol 2004; 22; 329-60

[14] De Maeyer E, De Maeyer-Guignard J. Immuno-modulating properties of interferons. Philos Trans R Soc Lond B Biol Sci 1982; 24/299(1094): 77-90.

[15] Goodier MR, Londei M. Lipopolysaccharide stimulates the proliferation of human $\mathrm{CD} 56^{+} \mathrm{CD}^{+} \mathrm{NKcells}$; a regulatory role of monocytesand IL-10. J Immunol 2000; 165; 139-47. 
[16] Kanevsky LM, Telford WG, Sapozhnikov AM, Kovalenko EL. Lipopolysaccharide induces IFN- $\gamma$ production in human NK cells. Front Immunol 2013; doi: 10.3389/fimmu.2013.00011.

[17] Schantz SP, Poisson L. Natural killer cell response to regional lymph node metastases. Arch Otolaryngol Head Neck Surg 1986; 112(5): 545-51.
[18] Wang S, Sun M, Gu C, et al. Expression of CD163, interleukin-10, and interferon-gamma in oral squamous cell carcinoma: mutual relationships and prognostic implications. Eur J Oral Sci 2014; 122(3): 202-9.

[19] Sheu BC, Lin RH, Lien HC, Ho HN, Hsu SM, Huang SC. Predominant Th2/Tc2 polarity of tumor-infiltrating lymphocytes in human cervical cancer. J Immunol 2001; 1/167(5): 2972-8.

Received: January 12, 2015

Revised: February 26, 2015

Accepted: March 03, 2015

(C) Naganawa et al.; Licensee Bentham Open.

This is an open access article licensed under the terms of the Creative Commons Attribution Non-Commercial License (http://creativecommons.org/licenses/by-nc/3.0/) which permits unrestricted, non-commercial use, distribution and reproduction in any medium, provided the work is properly cited. 